\title{
O PROJETO EXTENSÃO E A DOCÊNCIA: REFLEXÕES, DESAFIOS E AÇÕES NECESSÁRIAS NA PRÁTICA ACADÊMICA
}

\author{
Jammara Oliveira Vasconcelos de Sá (DLV/ UERN), jammaravasconcelos@gmail.com \\ Ângela Cláudia Rezende do Nascimento Rebouças (DLV/ UERN), ang-thi@hotmail.com \\ Bruna Gabrieli Morais da Silva Thorpe (PPCL/ UERN), bgabrieli@hotmail.com \\ Aylana Paula dos Santos Silva (Bolsista PROEX UERN), aylana silva@hotmail.com \\ DOI: 10.15628/rbept.2018.6871
}

Artigo submetido em dez/2017 e aceito em mar/2018

\begin{abstract}
RESUMO
Nosso artigo tem como objetivo refletir sobre as contribuições da primeira etapa da ação de extensão: "A oralidade e 0 ensino de língua materna - desafios e possibilidades (DLV/UERN)". Na esteira dos postulados de Bakhtin, que destacam a natureza dialógica dos gêneros discursivos concebendo-os como tipos relativamente estáveis (BAKHTIN, [19521953]/2003), servem, também, de amparo teórico para este artigo as importantes contribuições de Schneuwly e Dolz (2004) ao defenderem os gêneros orais e escritos como objetos importantes da relação ensino-aprendizagem de língua, assim como outros estudiosos da área que comungam dessa orientação para o ensino. Estas concepções com as quais coadunamos instigam-nos as seguintes indagações: como um maior conhecimento e sistematização dos gêneros orais pode auxiliar o professor em sua prática docente diária? Como as leituras em torno destas reflexões auxiliam discentes do curso de letras em sua formação profissional? A partir de um olhar dialético sobre as questões mencionadas, proporcionado pela nossa orientação metodológica com base na pesquisa-ação (THIOLLENT, 2011), a primeira etapa do nosso projeto de extensão já aponta algumas reflexões importantes. Nossas constatações iniciam-se por observarmos a necessidade de constantes leituras e atualizações em torno da temática abordada, o que tem sido um dos diferenciais na formação dos discentes envolvidos na ação. Neste sentido, evidenciamos, também, um importante crescimento acadêmico proporcionado pela articulação dialógica pertinente às pesquisas desta natureza.
\end{abstract}

Palavras-Chave: Projeto de extensão, gêneros orais, pesquisa-ação, comunidade acadêmica, prática docente.

\section{THE PROJECT EXTENSION AND TEACHING: REFLECTIONS, CHALLENGES AND ACTIONS NECESSARY IN ACADEMIC PRACTICE}

\begin{abstract}
Our article aims to reflect on the contributions of the first stage of the extension action: "Oral and mother tongue teaching - challenges and possibilities (DLV / UERN)". taking into account of Bakhtin's postulates, which emphasize the dialogical nature of discursive genres, conceiving them as relatively stable types (BAKHTIN, [1952-1953] / 2003), the important contributions of Schneuwly and Dolz (2004) defended the oral and written genres as important objects of the teaching-learning relationship of language, as well as other scholars of the area who share this orientation to teaching. These conceptions with which we co-operate instigate
\end{abstract}


the following questions: how can greater knowledge and systematization of oral genres assist the teacher in his daily teaching practice? How do the readings around these reflections help learners of the course of letters in their professional formation? From a dialectical perspective on the issues mentioned, provided by our methodological orientation based on action research (THIOLLENT, 2011), the first stage of our extension project already points out some important reflections. Our findings begin with observing the need for constant readings and updates around the topic addressed, which has been one of the differentials in the training of the students involved in the action. In this sense, we also show an important academic growth provided by the dialogical articulation pertinent to research of this nature.

Keywords: Extension project, oral genres, action research, academic community, teaching practice.

\section{APRESENTAÇÃO}

Este artigo tem como escopo refletir acerca das principais discussões empreendidas no decorrer da primeira etapa da ação de extensão: "A oralidade e o ensino de língua materna - desafios e possibilidades (DLV/UERN)" desenvolvido, em sua primeira parte, no âmbito acadêmico do curso de letras/ Língua Portuguesa.

Para isso, utilizamos como arcabouço teórico os estudos pioneiros de Bakhtin ([1952-1953]/2003) que concebe os gêneros como tipos, relativamente estáveis de enunciados, orais ou escritos que os sujeitos sociais utilizam de acordo com objetivos predefinidos através dos contextos nos quais estão inseridos. Apoiados nos postulados bakhtinianos e convergindo diretamente para a essência de nossa teoria de base, usamos também Schneuwly e Dolz (2004) que defendem os gêneros orais e escritos como objetos da relação ensino-aprendizagem e os apresentam como ferramentas importantes para o ensino de línguas.

Diante do desafio de suscitar tais reflexões, assumimos como orientação metodológica para as discussões empreendidas em nosso projeto de extensão a pesquisa-ação no que defende Thiollent (2011) acerca deste modelo de pesquisa. Desta forma, partimos da concepção de que, naturalmente, as reflexões que serviram de base para a escrita deste artigo, alimentam-se diretamente deste tipo de pesquisa. Este entendimento justifica incluirmos neste trabalho os principais pontos que nos orientam no que concerne ao modelo de pesquisa já mencionado.

Vislumbrando proporcionar ao leitor um panorama de alguns dos principais aspectos discutidos por nossa equipe, este artigo é composto de 8 seções, acrescidas do resumo/ abstract. São elas: a apresentação que oferece uma introdução do que discutimos no trabalho, no segundo tópico, proporcionamos um breve panorama do projeto de extensão cuja primeira etapa motivou o presente trabalho. Já na terceira seção, discutimos a concepção de gênero que embasa nosso trabalho com base no que defende Bakhtin ([1952-1953]/2003) para o tema. Chegamos, na quarta seção, à discussão dos gêneros como ferramentas de ensino baseados em Dolz e 
Schneuwly (2004) e outros estudos importantes para a temática. Na quinta seção, revelamos ao leitor aspectos importantes que nos levaram a decidir pela pesquisa-ação (THIOLLENT, 2011) no desenvolvimento do projeto que motivou este artigo. No sexto tópico, discorremos acerca de questões importantes no que concerne à oralidade como uma modalidade que oferece um apoio indispensável ao profissional docente de Língua Portuguesa (doravante LP). Já na sétima seção, mostramos algumas conclusões desta primeira etapa do projeto. Por fim, elencamos as referências bibliográficas que serviram de norte para a escrita deste artigo. Com base na organização retórica que apresentamos anteriormente, passamos, então, à segunda seção do artigo.

\section{NOSSO PROJETO DE EXTENSÃO: MOTIVAÇÕES ACADÊMICAS PARA O DIÁLOGO COM A PRÁTICA DISCENTE E DOCENTE EM LP}

Como já mencionado logo na introdução deste trabalho, o projeto de extensão que suscitou algumas reflexões motivadoras deste artigo é intitulado: "A oralidade e o ensino de língua materna: desafios e possibilidades" e tem sido desenvolvido pela equipe de membros da ação junto ao Departamento de Letras Vernáculas da Universidade do Estado do Rio Grande do Norte (UERN) no Campus Central, localizado na cidade de Mossoró(RN).

Em linhas gerais, o referido projeto, que se constitui de duas etapas, tem como escopo principal incluir o estudo e uso dos gêneros orais na prática docente do ensino de língua materna. Através dele, pretendemos, além de estimular o estudo dos principais pressupostos teóricos existente na temática abordada, possibilitar, também, a troca de experiências entre os discentes universitários membros do projeto e professores da rede pública da Escola Estadual Abel Coelho, também, localizada na cidade de Mossoró.

$\mathrm{Na}$ primeira etapa do projeto, foram realizadas leituras e discussões com os membros da equipe, composta por professoras e alunos da graduação e pós-graduação (alguns também autores deste artigo) da universidade já mencionada anteriormente. Durante esse primeiro momento, as ações deste projeto de extensão aconteceram no âmbito universitário, oportunizando importantes reflexões acerca das diferentes questões que perpassam o tema e que delineiam o aporte teórico do projeto. Já no segundo semestre do projeto mencionado que se realizará no ano letivo de 2018, darse-á o período de elaboração das atividades que vão subsidiar a equipe executora da ação para a culminância do projeto de extensão.

Esta fase futura terá como objetivo a interação através de oficinas de capacitação para os professores da Escola Estadual com a qual dialogamos acerca da necessidade de estudo e reflexão acerca da inclusão da oralidade como ferramenta valorosa e necessária ao profissional docente de Língua Portuguesa. Através das reflexões que pudemos desenvolver até agora, podemos admitir que esse é, realmente, um caminho indispensável para um ensino de língua materna que tenha como objetivo primeiro tornar o aluno 
proficiente e capaz de desenvolver-se através da língua de forma plena e satisfatória, nas diferentes esferas sociais nas quais já é enunciador ou ainda será, no desafiante exercício da linguagem.

Diante disso, passamos, em seguida, às discussões que representam o delineamento teórico ao qual nos dedicamos na primeira etapa de nossa empreitada e que tencionamos dar conta de alguns dos aspectos importantes que respaldaram, mesmo que de forma parcial, algumas das principais reflexões desenvolvidas no decorrer de nosso estudo e que suscitaram a proposição deste artigo.

\section{A CONCEPÇÃO DE GÊNERO DISCURSIVO QUE ASSUMIMOS}

As práticas docentes são, em geral, subsidiadas por diferentes concepções de língua e de ensino dentre as vertentes teóricas disponíveis. Em nosso projeto de extensão, mencionado anteriormente, procuramos refletir acerca do ensino de Língua Portuguesa contemplando a inclusão da modalidade oral a partir do trabalho com os gêneros discursivos. Em nossa concepção, esse entendimento deve ser um ponto de partida para a prática docente em língua materna, o que nos permite admitir, também, a convergência de nosso trabalho para a perspectiva bakhtiniana no que tange à concepção de língua materna, de gêneros discursivos e do dialogismo como fenômenos inerentes aos eventos que permeiam a linguagem.

Inicialmente, esta sintonia dá-se por comungarmos com o que defende Bakhtin ([1952-1953]/2003) acerca do fato de que a língua materna não chegar, em sua composição vocabular e em sua estrutura gramatical, ao nosso conhecimento a partir de dicionários e palavras, mas em enunciações concretas que nós mesmos ouvimos e reproduzimos na comunicação discursiva viva com as pessoas que nos rodeiam.

Desta forma, o autor ressalta que assimilamos as formas da língua somente através das formas típicas dos enunciados, ou seja, através dos gêneros do discurso que chegam à nossa experiência e à nossa consciência em conjunto e estreitamente vinculados.

Em "Estética da criação verbal", Bakhtin ([1952-1953]/2003) define os gêneros do discurso como tipos relativamente estáveis de enunciados elaborados em cada esfera de utilização (comunicação) da língua, funcionando como uma norma que intervém na estruturação dos enunciados, como fazem as normas da linguagem. Neste sentido, eles se definem pela combinação das seguintes dimensões essenciais: os conteúdos que podem ser ditos pelos gêneros e uma estrutura comunicativa particular, de configurações específicas de unidades linguageiras.

Nesta perspectiva, os gêneros do discurso diferenciam-se, em linhas gerais segundo o autor, como primários ou secundários conforme sua âncora com a situação em que se desenvolvem. Os gêneros que se articulam estreitamente com a situação interlocutiva em que estão inseridos caracterizam-se como primários ou simples. Já os que envolvem uma antecipação de conteúdos e uma maior complexidade na organização das 
unidades linguísticas são admitidos como secundários ou complexos. Salientamos que na diferenciação apontada por Bakhtin, segundo o autor, os gêneros primários, em geral, englobam gêneros orais provenientes, neste caso, das trocas verbais ordinárias.

Ainda no que concerne aos estudos bakhtinianos acerca da interatividade genérica, coadunamos com o que destaca Araújo, Rafael, Amorim (2016) acerca do fato de que os gêneros secundários podem ainda absorver e reelaborar gêneros primários, e podem também incorporá-los, na tentativa de representar uma interação cotidiana, a exemplo do que acontece em gêneros como o diário e as cartas.

É necessário apontar também, nesta perspectiva de análise para os gêneros discursivos, que a partir dessas trocas verbais o dialogismo, um dos aspectos inerentes ao processo interativo da linguagem, aflora como mais um dos fenômenos relacionados diretamente ao estudo dos gêneros discursivos nos postulados do autor.

Esta constatação identifica-se diretamente com o nosso projeto por considerarmos, também, que qualquer discussão contemplando os gêneros como ponto de partida para o ensino de língua materna, deve ser sensível às relações dialógicas que perpassam os gêneros. Neste sentido, esta orientação dialógica para o fenômeno tem sido evidenciada do decorrer desta primeira etapa da nossa ação de extensão, desde a elaboração e por todo o desenvolvimento da proposta até a fase que motivou este trabalho e que, ao nosso ver, são naturalmente intrínsecas ao projeto de extensão que temos desenvolvido.

Com base nas contribuições de Bakhtin e do Círculo, os enunciados se concretizam, segundo eles, por meio dos gêneros discursivos e, ao relacionarmos a perspectiva bakhtiniana com o ensino, é possível assumir que uma prática docente em sala de aula que desconsidere a realidade das esferas de comunicação, não aborda adequadamente os gêneros discursivos no ensino de língua materna (assim como também em outras línguas). Sendo indispensável para esta atividade, a contextualização desta prática com base nos gêneros, observando os sujeitos reais e o diálogo que existe entre locutor e interlocutor, ou seja, proporcionando, de fato, um ensino contextualizado para o aluno, próximo à realidade vivenciada por ele nas diferentes esferas sociais. A partir dessas orientações que servem de norte para nossas reflexões, passamos a seção seguinte deste trabalho.

\section{OS GÊNEROS DISCURSIVOS COMO INSTRUMENTOS: DESDOBRAMENTOS PARA O ENSINO}

É consenso entre muitos estudiosos da Linguística e, mais especificamente, entre os que se dedicam à análise dos gêneros discursivos dentre os quais podemos mencionar: Meurer, Bonini, Motta-Roth (2005), Faraco (2009), Marcuschi (2015) o fato de que os estudos de Bakhtin acerca do tema influenciaram diferentes vertentes nesta área.

Entre os desdobramentos dos postulados defendidos pelo autor, a influência da perspectiva bakhtiniana em trabalhos como os de Dolz e 
Schneuwly (2004), Schneuwly, Noverraz, Dolz (2004), Dolz e Gagnon (2015) e outros, no que tange ao tratamento dos gêneros como fenômenos que emergem da interação social, levando os estudiosos mencionados a apontálos como verdadeiras ferramentas didáticas para o ensino. As questões discutidas pelos estudiosos, no que diz respeito à concepção dos gêneros comparados à ferramentas necessárias a um ensino de língua, chamou-nos especialmente a atenção no período de definição da teoria de base que nortearia nosso projeto de extensão e nos levou a discutir, em nossos encontros, muitos dos pontos disponíveis nos trabalhos dos estudiosos.

Destacamos, contudo, que nossa intenção não consiste em esgotar as discussões acerca das contribuições dos autores no que diz respeito ao ensino de língua através dos gêneros discursivos, esta justificativa ocorre por reconhecermos a grande quantidade de trabalhos que existem nessa temática. Objetivamos, apenas, fundamentar através das obras mencionadas aqui e que serviram de base para a elaboração do projeto, assim como, para as discussões que ocorreram na primeira etapa de nossa ação de extensão alguns aspectos importantes defendidos pelos autores.

É necessário deixar claro, também, que alguns dos pontos importantes defendidos pelos autores e que admitimos serem valorosos para uma melhor compreensão da temática, já tivemos oportunidade de discutir em um artigo anterior intitulado: "Os gêneros como instrumentos de ensino: de Bakhtin aos PCNs " "(SÁ; LOPES, 2017)' o que nos permite silenciar alguns pontos defendidos ${ }^{2}$ pelos autores já mencionados nas seções 3 e 4 deste trabalho ou apenas mencionar, resumidamente, considerando o percurso argumentativo que adotamos neste artigo.

$\mathrm{Na}$ esteira da concepção do texto como unidade de base, tanto do ensino da produção oral e escrita, quanto da leitura e da recepção oral, Dolz e Gagnon (2015) advogam que os gêneros como mediadores essenciais da atividade humana associados às esferas das atividades específicas são vistos como ferramentas por atuarem em situações linguageiras com possibilidades de desenvolvimento e que se atualizam no uso, a partir dessa concepção podemos admitir o quão produtivo pode ser a prática docente com base nos gêneros discursivos, tema amplamente discutido na comunidade acadêmica e no ambiente escolar, esferas diretamente beneficiadas com esta prática.

De acordo com os autores, devido à sua natureza produtiva e marcada pela ação, os gêneros são, em sua essência, megainstrumentos ${ }^{3}$, o que os caracteriza como instrumentos totalmente eficientes para o ensino e a aprendizagem de línguas. Constatação, esta, com a qual concordamos e que

\footnotetext{
${ }^{1}$ Assim como o estudioso Dr. Clecio dos Santos Bunzen Jr. no prefácio da obra: " A oralidade em foco: conceitos, descrição e experiências de ensino (2016)", adotamos a variante PCNs para nos referir ao Parâmetros Curriculares Nacionais.

${ }^{2}$ Referimo-nos aos postulados de Schneuwly, Noverraz, Dolz (2004) acerca, por exemplo, das sequências didáticas como alternativas para o ensino.

${ }^{3}$ Termo usado por Schneuwly e Dolz (2004) na obra: SCHNEUWLY, B.; DOLZ, J. Os gêneros escolares -das práticas de linguagem aos objetos de ensino. In: SCHNEUWLY, B.; DOLZ, J. Gêneros orais e escritos na escola. Tradução e organização: Roxane Rojo e Glaís S. Cordeiro. Campinas, SP: Mercado de letras, 2004.
} 
motivou nossa vontade de investir no âmbito do projeto de extensão a partir deste norte.

Convergindo em muitos aspectos para o que defendem os estudos mencionados até aqui, os PCNs de Língua Portuguesa orientam que esta disciplina deve ter como objetivo principal na educação básica:

\begin{abstract}
Desenvolver no aluno seu potencial crítico, sua percepção das múltiplas possibilidades de expressão linguística, sua capacitação como leitor efetivo dos mais diversos textos representativos de nossa cultura. Para além da memorização mecânica de regras gramaticais ou das características de determinado movimento literário, o aluno deve ter meios para ampliar e articular conhecimentos e competências que possam ser mobilizadas nas inúmeras situações de uso da língua com que se depara, na família, entre amigos, na escola, no mundo do trabalho. (PCNEM, 1999, p. 59).
\end{abstract}

Nesta perspectiva, a concepção de língua como atividade interativa admitida no documento dialoga diretamente com o que defende Bakhtin ([1952-1953]/2003) acerca da natureza enunciativa dos fatores que envolvem a comunicação, assim como, para o que aponta Dolz e Schneuwly (2004) e Dolz e Gagnon (2015) acerca dos gêneros como ferramentas didáticas para o ensino de línguas, como afirmamos anteriormente e aspecto que acreditamos reforçar esta orientação como a mais produtiva para um ensino voltado para o objetivo de tornar o discente um falante proficiente de sua língua nas suas diversas esferas sociais.

A partir da tese de Dolz e Schneuwly (2004) na qual "é por meio dos gêneros que as práticas linguageiras se encarnam nas atividades dos alunos", Dolz e Gagnon (2015) alertam para as seguintes vantagens didáticas de um ensino através dos gêneros.

Primeiramente, os autores relembram que diante da diversidade e da heterogeneidade dos textos, o trabalho de reagrupamento dos gêneros facilita a organização do desenvolvimento dos conteúdos a serem ensinados. Outra vantagem importante consiste, segundo os estudiosos, nas possibilidades de se considerarem as práticas sociais de referência, pois a análise do uso dos gêneros constitui-se, neste caso, um referente por avaliar a pertinência e a eficácia comunicativa dos textos. Não deixando de salientar a importante vantagem dos aspectos associados às representações genéricas coletivas veiculadas por meio do gênero.

Neste sentido, um dos aspectos que norteia o nosso projeto no que diz respeito à contribuição positiva do processo de ensino e aprendizagem com base nos gêneros e que nos permite concordar com a visão dos autores acerca de que trabalhar, didaticamente, a partir das representações sociais facilita o sentido das aprendizagens, devendo este processo ser amparado por gêneros orais ou escritos. 
Diante do exposto, devemos admitir, contudo, que muito ainda temos que avançar para que a atenção dada aos gêneros escritos seja igual à concedida aos gêneros orais como ferramentas de ensino para as aulas de Língua Portuguesa. Essa questão dialoga perfeitamente com o objetivo central da nossa ação de extensão e nos levou à discussão de alguns pontos basilares apresentados na quinta seção deste artigo, após apontarmos a orientação metodológica que assumimos na ação de extensão cuja primeira etapa suscitou este trabalho.

\section{ESCOLHAS METODOLÓGICAS}

Como já mencionado, anteriormente, este artigo tem como principal motivação algumas das reflexões desenvolvidas na primeira etapa do projeto de extensão: "A oralidade e o ensino de língua materna: desafios e possibilidades". Partindo do pressuposto de que as decisões metodológicas assumidas, no decorrer da elaboração e execução da etapa que suscitou este trabalho, nos fizeram chegar até aqui e que, naturalmente, embasam nossas reflexões, discutiremos, brevemente, alguns detalhes de nossa metodologia, tencionando possibilitar ao leitor uma melhor compreensão do nosso percurso de pesquisa.

Neste sentido, ressaltamos que, entre os tipos de pesquisas que orientam a prática científica e acadêmica, em geral, defendemos que nosso projeto de extensão identifica-se, metodologicamente, com o que Thiollent (2011) classifica como um tipo de pesquisa-ação. Vejamos nas palavras do autor:

A pesquisa-ação é um tipo de pesquisa social que é concebida e realizada em estreita associação com uma ação ou com a resolução de um problema coletivo e no qual os pesquisadores e os participantes representativos da situação da realidade a ser investigada estão envolvidos de modo cooperativo e participativo. (THIOLLENT, 2011, p. 14).

Segundo o autor, este tipo de pesquisa foi introduzida no Brasil durante a década de sessenta pelo sociólogo brasileiro João Bosco Pinto. Proveniente das ciências sociais, a pesquisa-ação foi incorporada à educação e ao planejamento rural, sendo considerada como estratégia metodológica usada como instrumento de investigação e ação.

Neste sentido, a possibilidade de adaptação da pesquisa-ação revelase essencial à uma pesquisa como a nossa, que tem seu escopo voltado para a natureza dialógica da oralidade como ferramenta necessária à uma prática de ensino e aprendizagem de língua materna com foco nos gêneros discursivo inerentes à esta modalidade da língua e convergem para uma abordagem, também, dialética.

Assim, algumas características da pesquisa-ação guiaram-nos à escolha de tal caminho metodológico para execução do projeto de extensão como uma das alternativas mais satisfatórias, considerando o objeto de 
estudo e o contexto dinâmico em que ele se encontra. Descreveremos os principais pontos que consideramos relevantes para a escolha:

i) A natureza dinâmica do planejamento: ainda no que tange à caracterização da pesquisa-ação, é necessário salientar que, com base nos postulados de Thiollent (2011), ela desenvolve-se a partir de um planejamento flexível, diferentemente de outros tipos de pesquisa, uma vez que há sempre um "ir e vir" entre as inquietações que surgem no decorrer do percurso de pesquisa e que necessitam ser adaptadas em função dos contextos e da dinâmica central pertencente ao grupo de pesquisadores e à situação investigada;

ii) A flexibilidade processual: inerente a este tipo de pesquisa foi um dos aspectos com os quais temos nos identificado, fortemente, durante toda a primeira etapa do referido projeto e que se evidenciou em diferentes momentos. Entre os mais importantes, podemos apontar como exemplo: a elaboração e submissão da proposta da ação no âmbito da universidade, a divulgação do projeto junto à comunidade acadêmica na qual estamos inseridas, a composição dos membros da equipe, a escolha dos textos a serem lidos e discutidos nos encontros e, ainda, nas trocas e diálogos acadêmicos entre os membros da equipe executora da ação de extensão que se mostram extremamente produtivos para uma evolução satisfatória do que nos propomos através da pesquisa.

iii) A natureza reflexiva e dialética do objeto: outra característica deste tipo de pesquisa, e orientação que temos como norte em nosso trabalho, é a natureza reflexiva e dialética no desenvolvimento do objeto de pesquisa. Isso nos permite promover a condução das discussões, visando contemplar também a leitura e experiência do outro. Aspecto que defendemos aprimorar sensivelmente as reflexões que surgem em torno da temática investigada, em nosso caso, a inclusão da oralidade como prática docente essencial para o ensino da LP.

Acreditamos que nossa escolha metodológica converge, ainda, para o que defende Thiollent (2011) acerca da grande possibilidade de aprendizagem que a pesquisa-ação pode oferecer através do exercício de interação entre pesquisadores e participantes, promovendo, neste caso o encadeamento e a troca de aprendizado.

Diante do exposto, acreditamos ter deixado claro o delineamento metodológico que nos orientou na primeira etapa da pesquisa que motivou o presente artigo. Esse posicionamento nos permite avançar para a seção seguinte, em que discutimos algumas das questões que se revelaram mais importantes acerca da oralidade e que consideramos necessárias a uma adequada compreensão deste objeto de pesquisa. 


\section{A IMPORTÂNCIA DA ORALIDADE PARA O ENSINO DE LM}

Para iniciar esta seção, na qual tencionamos estabelecer algumas reflexões importantes acerca da relação entre a oralidade e o ensino de LP que se mostraram latentes no decorrer das leituras e discussões vivenciadas na primeira etapa do projeto que motivou este trabalho, precisamos esclarecer que diante da bibliografia existente acerca do tema, várias são as formas disponíveis no âmbito das pesquisas brasileiras para a abordagem da modalidade oral da língua.

Só para citar algumas delas podemos apontar: Koch $(1997,2015)$ com trabalhos sobre a descrição e a caracterização textual da modalidade falada, Dionisio (2001) acerca da análise da conversação, Alkmim (2001), Bagno (1999, 2000), Bortoni-Ricardo,(2004; 2005) com estudos dedicados aos aspectos sociolinguísticos que compreendem a língua falada, os Parâmetros Curriculares Nacionais para o ensino fundamental e médio (BRASIL, 1997, 1999) com orientações para a inclusão da oralidade na prática docente de LP e, ainda, trabalhos que têm como objetivo refletir acerca da oralidade como estratégia didática para 0 ensino de língua com base nos gêneros discursivos, dentre as quais estão: Marcuschi (2010, 2015), Ferreira (2014), Ferraz e Gonçalves (2015), Araújo, Rafael, Amorim (2016), Pereira e Silva (2016) entre outros.

É importante salientar que os trabalhos mencionados anteriormente representam, apenas, alguns dos que optamos por selecionamos para apontar neste artigo, haja vista reconhecermos a riqueza de outros trabalhos que também discutem a temática, mas que fogem ao escopo deste artigo e, ainda, do projeto de extensão que o motivou. Reforçamos, também, que dentre os estudos apontados, convergimos teoricamente para o que defende o último grupo de autores citados no parágrafo anterior. Esta decisão explicase pelo fato de os trabalhos mencionados, assim como os já discutidos ao longo do delineamento teórico deste artigo, harmonizarem-se perfeitamente com a perspectiva com qual trabalhamos no projeto de extensão que temos desenvolvido e que reconhecemos dar conta, mais adequadamente, da discussão que objetivamos suscitar no decorrer da primeira etapa do projeto.

Desta forma, no bojo das reflexões acerca da concepção interativa que perpassa o fenômeno da linguagem e do ensino de língua com base nos gêneros, concebemos a oralidade como uma prática social interativa para fins comunicativos que se apresenta sob variadas formas ou gêneros textuais fundados na realidade sonora. Podendo, nesta perspectiva, ser aprimorada. (MARCUSCHI, 2010)

A definição de Marcuschi ressalta a oralidade como uma modalidade extremamente necessária à prática docente diária para o ensino de língua materna aspecto que nos leva a concordar com o autor acerca dos avanços que um ensino voltado, também, para a inclusão desta modalidade pode proporcionar aos discentes, argumento que, como temos discutido neste artigo, embasa muitos trabalhos nesta área e que nos levou a investir na discussão desta temática, também no âmbito da extensão universitária, por evidenciarmos no decorrer de nossa pesquisa o quanto podem ser produtivas 
ações voltadas para a aproximação entre as discussões e pesquisas empreendidas na universidade e a comunidade de docentes de LP.

Faz-se necessário ressaltar também que, concordamos com Araújo, Rafael, Amorim (2016) ao destacarem, na esteira do que defende Bakhtin, que a perspectiva dialógica de abordagem da oralidade permite-nos considerar os dados desta modalidade como realmente eles são: manifestações concretas da linguagem, enfeixadas, neste caso, em gêneros primários ou secundários dialogicamente definidos para interlocutores em condições ativas de reagir e responder ao que lhes foi enunciado na situação em questão.

Ainda acerca da natureza dialógica da linguagem, Bakhtin ([19521953]/2003) ressalta que a oralidade mostra-se de suma importância como dado linguístico, pelo fato de, segundo ele, ser através dela que, primariamente, se manifestam as enunciações, tanto no círculo doméstico e familiar, quanto em outros círculos que exigem a presença face a face dos interlocutores e também exigem a "palavra" do enunciador, estejam eles envolvidos presencialmente ou não na situação enunciativa. Nesta perspectiva, defendemos, no que tange ao ensino, a inclusão cada vez mais sistemática e orientada pelos gêneros pertinentes à modalidade oral da língua, visando o desenvolvimento dos discentes de LP.

Neste sentido, destacamos que a orientação para a abordagem da oralidade sugerida pela Linguística dos usos da linguagem com base no ensino de língua materna a partir dos gêneros discursivos orais, ampara as recomendações dos PCNs para o ensino de LP. Vejamos em um dos trechos do documento:

\begin{abstract}
Pensar o ensino de Língua Portuguesa no ensino médio significa dirigir a atenção não só para a literatura ou para a gramática, mas também para a produção de textos e a oralidade. A exploração da literatura, da gramática, da produção de textos e da oralidade pressupõe 0 desenvolvimento de competências e habilidades distintas, ligadas à leitura, aos conhecimentos linguísticos, à escrita e à fala. Assim, na articulação entre conceitos, conteúdos e competências, na elaboração ou escolha dos materiais didáticos, parece interessante contemplar esses quatro grandes eixos. (PCNEM, 1999, p. 67).
\end{abstract}

Como podemos ler nesta passagem dos parâmetros, é sugerido um tratamento igualitário entre os quatro eixos basilares ao ensino de LP (literatura, gramática, produção de textos e oralidade). A concepção defendida ao longo do documento eleva a oralidade ao mesmo patamar de importância dos outros três eixos do ensino. Aspecto que, na nossa concepção, vem justificar uma maior preocupação em pesquisas que possibilitem a indicação de estratégias direcionadas para a realização dessa inclusão na prática docente diária do profissional de LP.

O debate suscitado pelos parâmetros justifica pesquisas como a que temos empreendido em nosso projeto de extensão, pois é evidente que a modalidade escrita já é, consideravelmente, contemplada na esfera escolar e 
inclusive na rotina universitária em geral. Modalidade esta que se realiza de diferentes formas e através de diferentes gêneros. Aspecto que, na nossa concepção, confirma o fato de que inclusive na esfera acadêmica a oralidade ainda é pouco aproveitada, considerando todo o potencial de ensino e aprendizagem que ela pode possibilitar.

É no desdobramento das questões apresentadas neste artigo que nosso projeto de extensão vem ganhando espaço e reafirmando a urgência de trabalhos que discutam acerca de uma maior inclusão da oralidade na prática docente do ensino de LP e proponham ações que inter-relacionem o que já existe nas pesquisas da área com a realidade docente atual, possibilitando uma dinâmica real entre teoria e prática docente de LP.

Desta forma, as reflexões oriundas desta primeira etapa da ação apontam para o fato de que a prática docente em LP contemplando, neste caso também, a oralidade estabelece uma ruptura necessária na cultura grafocêntrica que coloca a escrita como modalidade predominante nas aulas de LP, realidade que durante muitas décadas determinou os rumos do ensino de LP no Brasil e que, conforme os estudos e documentos nesta área, deve ser repensada no âmbito da docência de língua materna.

\section{CONCLUSÃO}

Diante das discussões que tecemos até aqui, é inegável a necessidade de um ensino de LP voltado para uma atenção maior acerca da inclusão da oralidade na prática docente diária visando uma valorização e sistematização desta modalidade da língua, ainda pouco aproveitada nas aulas de língua materna no cenário educacional brasileiro.

Reconhecemos que muito já avançamos acerca dos trabalhos que abordam a temática desde a publicação dos PCNs na década de 90. Contudo, muito ainda precisamos discutir e avançar para que a modalidade oral e a modalidade escrita tenham, realmente, um tratamento igualitário no exercício do ensino e aprendizagem de LP.

Outro aspecto que merece destaque está no âmbito da formação discente de alunos do curso de Letras que vivenciam reflexões acerca desta temática. Neste sentido, temos evidenciado o quanto pode ser motivador, para os docentes em formação, vislumbrar estratégias mais assertivas para o trabalho com os gêneros orais, assim como recomendam os PCNs no Brasil. Assim, os aspectos apresentados até aqui reafirmam, ainda mais, a relevância das ações de pesquisa e extensão no cenário acadêmico atual, podendo atuar como uma excelente estratégia de diálogo para 0 aprofundamento de temas como o que abordamos neste artigo. É notório o fortalecimento, através do conhecimento, de todos os colaboradores envolvidos na pesquisa que motivou este trabalho, o que cria um lócus ativo de observação destas experiências com o objetivo de fomentar excelentes debates acadêmicos, no decorrer do processo de socialização do saber. 


\section{REFERÊNCIAS}

1. ALKMIM, T. M. Sociolinguística. In: MUSSALIM, F.; BENTES, A. C. (org). Introdução à linguística: domínios e fronteiras. São Paulo: Cortez, 2001. Vol. 1.

2. ARAÚJO, D. L.; RAFAEL, E.L.; AMORIM, K. V. Estudos de oralidade: o ponto de vista na percepção do objeto e suas implicações para a formação docente. In: ARAÚJO, D. L., Joaquim; SILVA, W. M.(orgs). A oralidade em foco: conceitos, descrição e experiências de ensino. Campinas, SP: Pontes Editores, 2016.

3. BAGNO, M. Preconceito linguístico: o que é, como se faz. São Paulo: Edições Loyola, 1999.

4. _. Dramática da língua portuguesa: tradição gramatical, mídia e exclusão social. São Paulo: Edições Loyola, 2000.

5. BAKHTIN, M. M. ([1952-1953]). Os gêneros do discurso. In: Estética da criação verbal. Trad. Paulo Bezerra. 4. ed. São Paulo: Martins Fontes, 2003.

6. BORTONI-RICARDO, S. M. Educação em Língua Materna: A Sociolinguística em Sala de Aula. São Paulo: Parábola Editorial, 2004.

7. Nós cheguemu na escola, e agora? Sociolinguística e Educação. São Paulo: Parábola Editorial, 2004.

8. BRASIL. Secretaria de Educação Fundamental. Parâmetros curriculares nacionais: introdução aos parâmetros curriculares nacionais / Secretaria de Educação Fundamental. - Brasília: MEC/SEF, 1997. 126p.

9. BRASIL. Secretaria de Educação. Parâmetros curriculares nacionais+ ensino médio: Linguagens, códigos e suas tecnologias orientações educacionais complementares aos parâmetros curriculares nacionais / Secretaria de Educação. Brasília : MEC/SEF, 1999. 241p.

10. DIONISIO, A. P. Análise da conversação. In: MUSSALIM, F.; BENTES, A. C. (org). Introdução à linguística: domínios e fronteiras. São Paulo: Cortez, 2001. vol. 2.

11. DOLZ, J.; SCHNEUWLY, B.; H., Sylvia. O oral como texto: como construir um objeto de ensino. In: DOLZ, Joaquim; SCHNEUWLY, Bernard. Gêneros orais e escritos na escola. Campinas, SP: Mercado das Letras, 2004.

12. SCHNEUWLY, B.; NOVERRAZ, M.; DOLZ, J. Sequência didática para o oral e a escrita: apresentação de um procedimento. In: SCHNEUWLY, B.; DOLZ, J. Gêneros orais e escritos na escola. Tradução e organização: Roxane Rojo e Glaís S. Cordeiro. Campinas, SP: Mercado de letras, 2004.

13. DOLZ, J.; GAGNON, R. O gênero de texto, uma ferramenta didática para desenvolver a linguagem oral e escrita. In: Gêneros orais no ensino. BUENO, L.; COSTA-HÜBES, T. C. (orgs). Campinas, SP: Mercado das 
Letras, 2015.

14. FARACO, C. A. Linguagem \& diálogo: as ideias linguísticas do círculo de Bakhtin. São Paulo: Parábola editorial, 2009.

15. FERREIRA, E. C. F. A oralidade como objeto de ensino: por uma perspectiva de desenvolvimento da língua oral a partir do gênero debate. 226 p. Tese (Doutorado em Linguística). Universidade Federal do Ceará, Fortaleza, 2014.

16. FERRAZ, M. R. R.; GONÇALVES, A. V. Gêneros orais: práticas de ensino sem evidência. In: BUENO, L.; COSTA-HÜBES, T. C. (orgs). Gêneros orais no ensino. Campinas, SP: Mercado das Letras, 2015.

17. $\mathrm{KOCH}$, I. G. V. A inter-ação pela linguagem. São Paulo: Contexto, 2015.

18.

O Texto e construção dos sentidos. São Paulo: Contexto, 1997.

19. MARCUSCHI, L. A. Da fala para a escrita: atividades de retextualização. 4. Ed. São Paulo: Cortez, 2010.

20. . Produção textual, análise de gêneros e compreensão. São Paulo: Parábola, 2015.

21. MEURER; J. L.; BONINI, A.; MOTTA-ROTH, D. (org.). Gêneros: teorias, métodos e debates. São Paulo: Parábola editorial, 2005.

22. PEREIRA, B. A.; SILVA, W. O debate no espaço escolar: objeto de ensino ou estratégia metodológica. In: ARAÚJO, D. L., Joaquim; SILVA, W. (orgs). A oralidade em foco: conceitos, descrição e experiências de ensino. Campinas, SP: Pontes Editores, 2016.

23. SÁ, J. O. V.; LOPES, L. M. Os gêneros como instrumentos de ensino: de Bakhtin aos PCNs. In: Costa e Silva, G.; Lopes, M. S.; Monteiro, R. M. P. (orgs). Experiências em ensino, pesquisa e extensão na universidade: caminhos e perspectivas. Fortaleza: Imprece, 2017.

24. SCHNEUWLY, B.; DOLZ, J. Os gêneros escolares - das práticas de linguagem aos objetos de ensino. In: SCHNEUWLY, B.; DOLZ, J. Gêneros orais e escritos na escola. Tradução e organização: Roxane Rojo e Glaís S. Cordeiro. Campinas, SP: Mercado de letras, 2004.

25. THIOLLENT, Michel. Metodologia da pesquisa-ação. 18. ed. São Paulo. Cortez, 2011. 